\title{
Magnetically Collimated Energy Transport by Laser Generated Relativistic Electrons
}

M. H. Key

February 8, 2001

U.S. Department of Energy

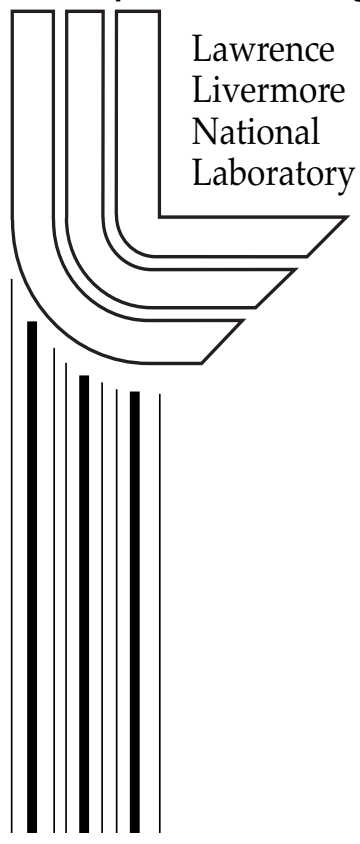




\section{DISCLAIMER}

This document was prepared as an account of work sponsored by an agency of the United States Government. Neither the United States Government nor the University of California nor any of their employees, makes any warranty, express or implied, or assumes any legal liability or responsibility for the accuracy, completeness, or usefulness of any information, apparatus, product, or process disclosed, or represents that its use would not infringe privately owned rights. Reference herein to any specific commercial product, process, or service by trade name, trademark, manufacturer, or otherwise, does not necessarily constitute or imply its endorsement, recommendation, or favoring by the United States Government or the University of California. The views and opinions of authors expressed herein do not necessarily state or reflect those of the United States Government or the University of California, and shall not be used for advertising or product endorsement purposes.

This work was performed under the auspices of the U. S. Department of Energy by the University of California, Lawrence Livermore National Laboratory under Contract No. W-7405-Eng-48.

This report has been reproduced directly from the best available copy.

Available electronically at http://www.doc.gov/bridge

Available for a processing fee to U.S. Department of Energy

And its contractors in paper from

U.S. Department of Energy

Office of Scientific and Technical Information

P.O. Box 62

Oak Ridge, TN 37831-0062

Telephone: (865) 576-8401

Facsimile: (865) 576-5728

E-mail: reports@adonis.osti.gov

Available for the sale to the public from

U.S. Department of Commerce

National Technical Information Service

5285 Port Royal Road

Springfield, VA 22161

Telephone: (800) 553-6847

Facsimile: (703) 605-6900

E-mail: orders@ntis.fedworld.gov

Online ordering: http://www.ntis.gov/ordering.htm

OR

Lawrence Livermore National Laboratory

Technical Information Department's Digital Library

http:/ / www.llnl.gov/tid/Library.html 


\title{
Final Report
}

LDRD 00-ERD-45

\section{Magnetically Collimated Energy Transport by Laser Generated Relativistic Electrons}

\author{
M. H. Key (PI)
}

\section{Background}

The possibility of fast ignition of thermo-nuclear fusion ${ }^{1}$ is stimulating research interest and activity worldwide. Fast ignition (FI) offers significantly higher gain than conventional spark ignition $^{2}$ and the high gain opens the way to an efficient fusion energy producing cycle with laser drivers ${ }^{3}$.

The key to FI is the efficient transport of energy from a short pulse laser beam, the ignitor, to a small ignition spark in compressed deuterium-tritium fuel. The primary candidate process enabling such energy transfer, is the absorption of laser light and its conversion into a beam of relativistic electrons, which heats the $\operatorname{spark}^{4}$. Theory has predicted self-induced magnetic collimation of the electron beam ${ }^{5}$, which could enable efficient transport from the absorption point to the ignition spark. Experiments are required to understand this highly complex process which involves currents in the electron beam, which greatly exceed the Alfven current limit ${ }^{6}$ (at which the Larmor radius of an electron in the magnetic field associated with by the current is smaller than the radius of the beam). Almost complete current compensation by cold electron return current is therefore required. The oppositely directed hot and cold electron flows initiate strong growth of the Weibel instability, which causes the currents to break up into microscopic filaments ${ }^{7}$. The net forward current at less than the Alfven limit however generates a magnetic field, which acts to collimate the overall electron flow ${ }^{5}$.

Experiments with the chirped pulse amplification (CPA) petawatt laser ${ }^{8}$ at LLNL have shown efficient conversion of laser energy to relativistic electrons ${ }^{4}$. Heating to 300 $\mathrm{eV}$ has been deduced from $\mathrm{x}$-ray spectra of $\mathrm{Al}$ layers in a solid $\mathrm{CH}$ targets ${ }^{9}$ and temperatures exceeding $500 \mathrm{eV}$ have been inferred from the neutron yield of D-D thermonuclear fusion in solid $\mathrm{CD}_{2}$ targets $^{2}$. Collimated energy transport in a columnar annular pattern has been seen in images of thermal x-ray emission of $\mathrm{Al}$ and $\mathrm{Au}$ layers in $\mathrm{CH}$ targets as illustrated in figure $1^{10}$. Work in other laboratories worldwide has given additional evidence of well-collimated energy transport ${ }^{11,12}$. 


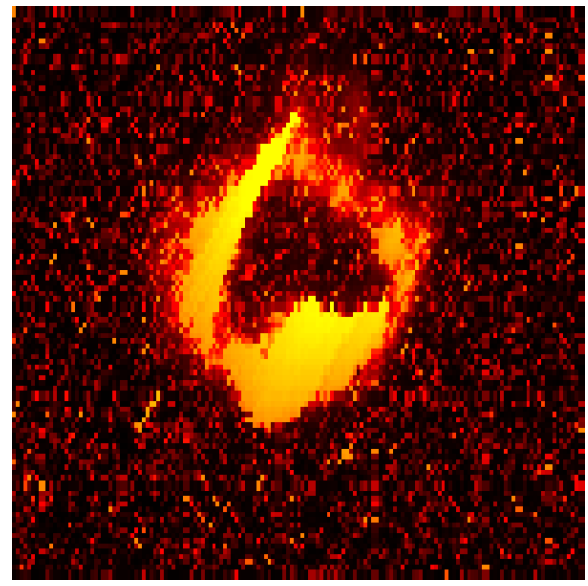

$15 \mu \mathrm{m}$ depth

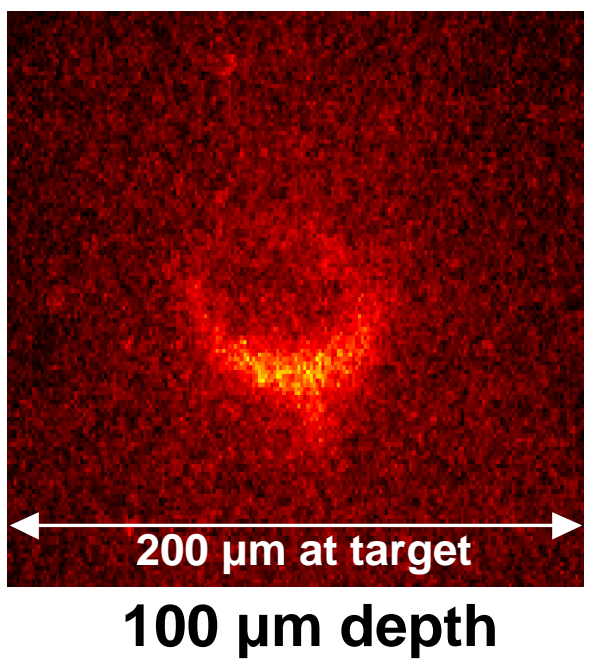

Figure 1. X-ray images of $0.5 \mu \mathrm{m}$ thick Al layers at depths of 15 and $100 \mu \mathrm{m}$ in solid $\mathrm{CH}_{2}$. Targets were irradiated with $5 \mathrm{ps}, 400 \mathrm{~J}$ pulses. The pattern of heating is annular and collimated over the $100 \mu \mathrm{m}$ range of the experiment.

In the summer of 1999, there was a major review of the US Fusion Energy program conducted in part through a fusion community Summer Study at Snow Mass in Colorado. We participated actively in that study and made the case for fast ignition in general $^{13}$ and for the study of energy transport in particular ${ }^{14}$. Subsequent recommendations by the Fusion Energy Sciences Advisory Committee (FESAC) opened up the possibility of proposing concept explorations for inertial fusion energy within the Office of Fusion Energy Sciences (OFES) program.

\section{The goals of the project}

The principal goal of this one-year exploratory LDRD project was to devise new ways to improve the measurement of energy transport by relativistic electrons and to negotiate and plan collaborative FI experiments. The experiments would be carried out at laboratories overseas, which alone had lasers of sufficient power and energy after the closure of the Nova petawatt laser at LLNL. A further goal was to propose research into fast ignition in the OFES program.

The LDRD project was successful in both its main objectives. 


\section{Collaborations and a new OFES project}

Collaborations overseas were established with scientific teams using $100 \mathrm{TW}, 1$ ps CPA laser facilities at the Rutherford Appleton Laboratory in the U.K., the LULI Laboratory in France and the ILE Laboratory in Japan. Two new diagnostic instruments were planned for these experiments. One uses imaging with a few micron resolution, of Planckian XUV emission at $60 \mathrm{eV}$ photon energy to give more sensitive measurements of the temperature pattern on the rear surface of an electron-heated target. The second uses spherical crystal imaging of $\mathrm{K} \alpha \mathrm{x}$-ray fluorescence from buried layers of $\mathrm{Ti}$ and $\mathrm{Cu}$ to map with a less than $10 \mu \mathrm{m}$ resolution the pattern of electron energy transport inside solid targets.

A US partnership was developed between LLNL, General Atomics, University of California at Davis, Princeton University and University of California at San Diego. As partners we made a joint proposal to the OFES for concept exploration studies in fast ignition which was funded with effect from July 2000. This US team will undertake a four-year program of work to investigate fast ignition (primarily the energy transport issues) through international collaboration in experiments on high intensity laser facilities over-seas. Theory and numerical modeling is included in the project. Links have also been established with related FI target design activity and with reactor studies funded by OFES.

\section{Experimental study of proton beam generation}

In preparation for the work overseas, smaller scale experiments were begun using the JanUSP laser at LLNL. JanUSP is currently the most powerful laser facility in the U.S.A. and is capable of producing intensities on target of approximately $10^{20} \mathrm{Wcm}^{-2}$ in $100 \mathrm{TW}, 100 \mathrm{fs}, 10 \mathrm{~J}$ pulses. These experiments were directed towards further study of an exciting discovery, which had been made in the petawatt experiments at the Nova laser ${ }^{15}$. This is the generation of highly collimated intense high energy proton beams from the rear surface of laser irradiated thin foil targets. The mechanism of production of these beams had become somewhat controversial in the scientific community as others had put forward a model, which differed from our original explanation. We had postulated that relativistic electrons penetrating through thin foil targets created a high electric field in a Debye-sheath on the rear surface, which then accelerated ions into vacuum ${ }^{16}$. The contrary explanation assumed that laser light pressure at the front surface drove ions through the target $^{17}$. 
Data from JanUSP provided further evidence for the Debye sheath mechanism. The variation of proton energy with thickness of the target was measured as shown in figure 2. $20 \mathrm{MeV}$ protons from the front surface would experience negligible energy loss in travelling through the $100 \mu \mathrm{m}$ maximum thickness of the targets used in the experiment, yet there was a fall in energy to about $5 \mathrm{MeV}$ with increasing target thickness $\boldsymbol{L}$ from 2 to $100 \mu \mathrm{m}$. This can be understood through the reduction in number density $\boldsymbol{N}_{\boldsymbol{e}}$ of hot electrons (scaling as $\boldsymbol{L}^{-1}$ ) trapped electro-statically in thicker targets. There is a corresponding reduction (scaling as $\boldsymbol{N}_{e}{ }^{0.5}$ ), in the electric field of the Debye sheath and therefore of the proton energies.

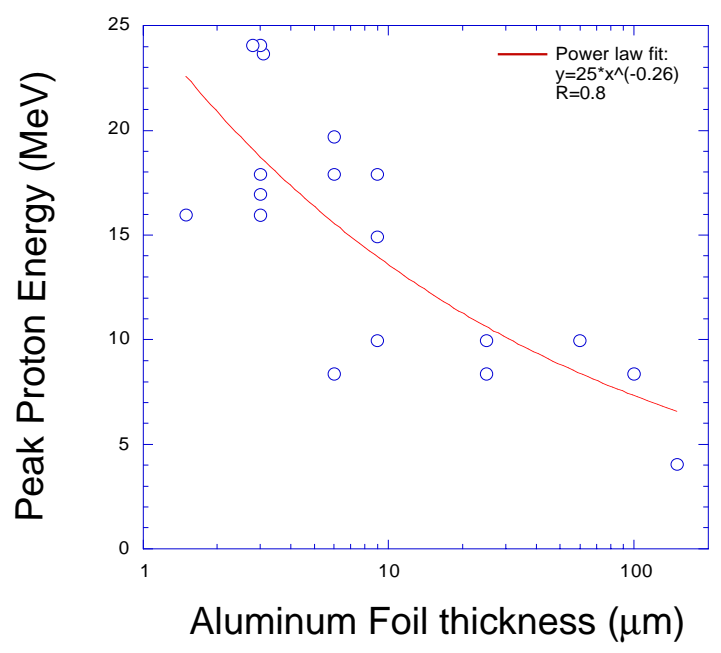

Figure 2. Variation of maximum proton energy with target thickness for Al targets irradiated with 100fs, $10 \mathrm{~J}$ pulses at the JanUSP laser.

The JanUSP work also gave data on the effective source size of the proton beam. This was measured from radio-chromic film images of the penumbral shadow of an obstacle placed in the beam and was found to be to be only $40 \mu \mathrm{m}$, as illustrated in Figure 3 . The cone angle of the beam can also be measured from the same images and hence the emittance. The data showed that the normalized emittance is less than $1.0 \pi \mathrm{mm}$ mrad at the maximum proton energy, and thus better than that of the beam injected into accelerators such as the proton Linac at CERN. 


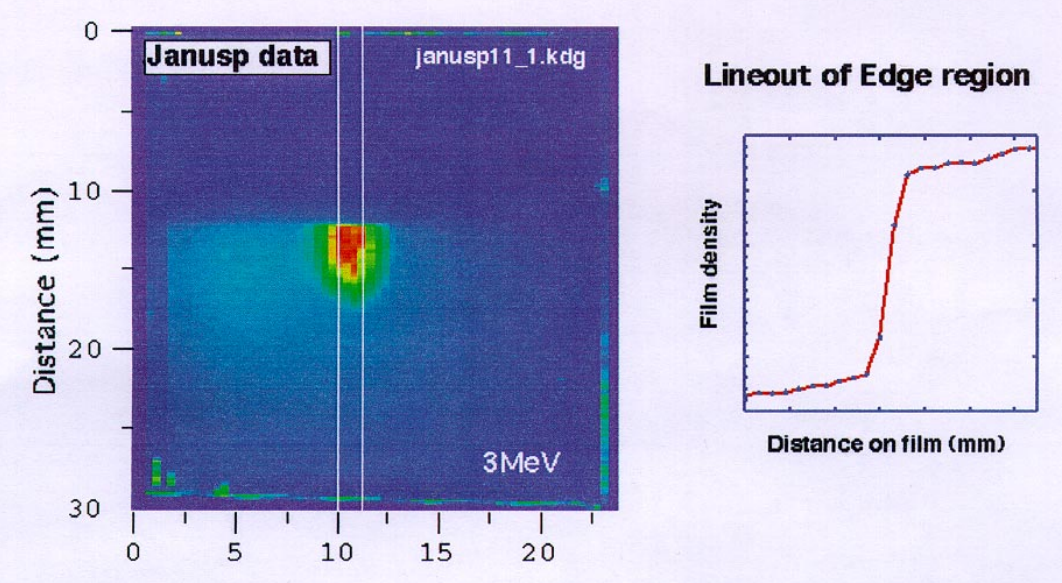

Figure 3. Penumbral image of $>3 \mathrm{MeV}$ protons with an edge obscuration in the beam, recorded on radiochromic film at JanUSP (left) and line out through the penumbral shadow (right). The inferred source size is $40 \mu \mathrm{m}$.

The discovery of the proton beam also enabled us to formulate a new idea for FI using protons to transport the energy. In this concept ballistic focusing of proton beams generated at a thin target with a concave spherical rear surface would deliver energy to the ignitor spark. The advantage is much simpler energy transport physics. The key question to be resolved is how to obtain efficient conversion of laser energy to protons in a 15 to $25 \mathrm{MeV}$ energy band required to limit the transit time spread of arrival of the protons at the ignitor spark. A paper outlining the concept was recently accepted for publication in the Physical Review Letters ${ }^{18}$.

\section{Conclusions}

In conclusion, the short investigative project proved very successful with some new scientific results in the area of proton beams and the launching of a new OFES program in concept exploration of fast ignition.

\section{Acknowledgements}

My thanks are due to my co- investigators $\mathrm{R} \mathrm{R}$ Freeman and $\mathrm{H} \mathrm{A}$ Baldis and to project scientists A J MacKinnon, J A Koch and R A Snavely. Valuable assistance in theoretical work was given by S Hatchett. R Stephens of General Atomics played a vital role in developing the OFES project .I am grateful also for collaboration with $\mathrm{T} E$ Cowan, M Roth ,P Patel and the operations staff of the JanUSP laser. 


\section{References}

${ }^{1}$ M. Tabak, J. Hammer, M. E. Glinsky, W. L. Kruer, S. C. Wilks, J. Woodworth, E. M. Campbell, M. D. Perry, and R. J. Mason, Phys. Plasmas 1, 1626 (1994)

${ }^{2}$ M. H. Key, E. M. Campbell, T. E. Cowan, S. P. Hatchett, et al. J. Fusion Energy 17, 231 (1998)

${ }^{3}$ W R Meier andC W von Rosenberg. Fusion technology 21 1552(1992)

${ }^{4}$ M. H. Key, K. Estabrook, B. Hammel, S. Hatchett, D. Hinkel, J. Kilkenny, J. Koch, et.al. Phys. Plasmas 5, 1966 (1998), T E Cowan et al . Laser and Particle beams,17773,(1999)

5 J. R. Davies, A. R. Bell, M. G. Haines, and S. M. Guérin, Phys. Rev. E 56, 7193 (1997). A. R. Bell, J. R. Davies, and S. M. Guérin, Phys. Rev. E 58, 2471 (1998). ). J. R. Davies, A. R. Bell, and M. Tatarakis, Phys. Rev. E 59, 6032 (1999)

${ }^{6}$ H Alfven, Phys, Rev,Lett. 55, 425,(1939)

${ }^{7}$ M. Honda, J. Meyer-ter-Vehn, A. Pukhov, Phys. Plasmas 7, 1302 (2000)

${ }^{8}$ M. D. Perry, D. Pennington, B. C. Stuart, G. Tietbohl, J. A. Britten, C. Brown, S. Herman, B. Golick, M. Kartz, J. Miller, H. T. Powell, M. Vergino, and V. Yanovsky, Opt. Lett. 24, 160 (1999)

${ }^{9}$ J. A. Koch, C. A. Back, C. Brown, K. Estabrook, B. A. Hammel, S. P. Hatchett, M. H. Key, et.al. Lasers and Particle Beams 16, 225 (1998)

${ }^{10}$ J. A. Koch, S. P. Hatchett, M. H. Key, R. W. Lee, D. Pennington, R. B. Stephens, and M. Tabak, Inertial Fusion Sciences and Applications 99, Eds. C. Labaune, W. Hogan, K. Tanaka (Elsevier, Paris, 2000), pg. 463. J A Koch, R R Freeman, S P Hatchett, M H Key ,R.W.Lee, D Pennington, R .B Stephens, M Tabak. Phys Rev E ( submitted) (2000)

${ }^{11}$ R. Kodama, presented at the 4th International Workshop on the Fast Ignition of Fusion Targets, Paris, March 2000

${ }^{12}$ M Tatarakis et al. Phys Rev Lett 81999 (1998)

${ }^{13}$ M H Key .Fast Ignition 1999 Fusion Summer Study -Inertial Fusion Concepts working group,. Snowmass , ( 1999 ) R B. Stephens, M. Key, W. Meier, R. Moir and M. TabakThe Case for Fast Ignition as an IFE Concept Exploration Program 1999 Fusion Summer Study (1999) UCRL-MI-135800

${ }^{14}$ M H Key Energy transport in fast ignition 1999 Fusion Summer Study -Energy transport working group .Snowmass . (1999)

${ }^{15}$ R. A. Snavely, M. H. Key, S. P. Hatchett, T. E. Cowan, M. Roth, T. W. Phillips, M. A. Stoyer, E. A. Henry, T. C. Sangster, M. S. Singh, S. C. Wilks, A. MacKinnon, A. Offenberger, D. M. Pennington, K. Yasuike, A. B. Landon, B. F. Lasinski, J. Johnson, M. D., Phys Rev. Lett. 85, 2945, (2000)

${ }^{16}$ Hatchett APS S. P. Hatchett, C. G. Brown, T. E. Cowan, E. A. Henry, J. Johnson, M. H. Key, J. A. Koch, et.al, Phys. Plasmas 7, 2076 (2000)

${ }^{17}$ K. Krushelnick et al. Physics of Plasmas, 7, 2055 (2000). E. L. Clark et al.. Phys. Rev. Lett. 84, 670, (2000)

${ }^{18}$ M. Roth, T. Cowan, M. Key, S. Hatchett, C. Brown, M. Christl, W. Fountain, J. Johnson, T. Parnell, D. Pennington, M. D. Perry, T. W. Phillips, R. Snavely, S. C. Wilks, K. Yasuike, Phys. Rev. Lett. 86, 436 (2001) 